\title{
Polo-like Kinase 1 Inhibitor NMS-1286937
}

National Cancer Institute

\section{Source}

National Cancer Institute. Polo-like Kinase 1 Inhibitor NMS-1286937. NCI Thesaurus.

Code C88313.

An orally bioavailable, small-molecule Polo-like kinase 1 (PLK1) inhibitor with potential antineoplastic activity. Polo-like kinase 1 inhibitor NMS-1286937 selectively inhibits PLK1, inducing selective G2/M cell-cycle arrest followed by apoptosis in a variety of tumor cells while causing reversible cell-cycle arrest at the G1 and G2 stages without apoptosis in normal cells. PLK1 inhibition may result in the inhibition of proliferation in PLK1overexpressing tumor cells. PLK1 is a serine/threonine protein kinase crucial in the regulation of mitosis. 